\title{
Retraction Note to: Nanozyme Based Detection of Heavy Metal lons and its Challenges: A Minireview
}

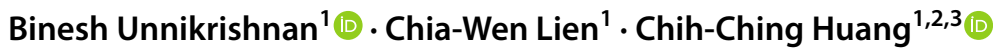

Published online: 23 March 2020

(c) The Nonferrous Metals Society of China 2020

Retraction to: Journal of Analysis and Testing (2019) 3:206-218 https://doi.org/10.1007/s41664-019-00110-2

The publisher has retracted this article [1] due to an operational error during the publication process. The authors agree with this retraction.

\section{Reference}

1. Unnikrishnan B, Lien C, Huang C. Nanozyme Based Detection of Heavy Metal Ions and its Challenges: A Minireview. J Anal Test. 2019;3:206-18.

The original article can be found online at https://doi.org/10.1007/ s41664-019-00110-2.

Chih-Ching Huang

huanging@ntou.edu.tw

1 Department of Bioscience and Biotechnology, National Taiwan Ocean University, 2, Beining Road, Keelung 20224, Taiwan

2 Center of Excellence for the Oceans, National Taiwan Ocean University, Keelung 20224, Taiwan

3 School of Pharmacy, College of Pharmacy, Kaohsiung Medical University, Kaohsiung 80708, Taiwan 